\title{
Arrhythmias in Patients With Pulmonary Hypertension; A Narrative Review of the Current Literature
}

\author{
Dirk Bandorski ${ }^{{ }^{*}}$, Reinhard Hoeltgen ${ }^{2}$ \\ ${ }^{1}$ University of Giessen and Marburg Lung Center (UGMLC), member of the German Center for Lung Research (DZL), \\ Klinikstrasse 33, 35392 Giessen, Germany \\ ${ }^{2}$ Klinikum Westmünsterland, St. Agnes-Hospital Bocholt Rhede, Medical Clinic 1 - Cardiology/Electrophysiology, \\ Barloer Weg 125, 46397 Bocholt, Germany
}

*Corresponding Author: Dirk Bandorski, MD, FESC, FACC, Member of the German Center for Lung Research (DZL), University of Giessen and Marburg Lung Center (UGMLC), Klinikstrasse 33, 35392 Giessen, Germany. Tel: +49-64198542351, Fax: +49-641-98542359, Email: dirk.bandorski@khw.med.uni-giessen.de

Received April 18, 2018; Accepted January 21, 2018; Online Published April 18, 2018

\begin{abstract}
Incidence and prognostic relevance of supraventricular arrhythmias were evaluated in nine studies. These studies investigated patients with different forms of pulmonary hypertension. Supraventricular arrhythmias were more often found in patients with group two pulmonary hypertension. Common findings in these patients were elevated right atrial pressure and diameters and reduced tricuspid annular plane systolic excursion (TAPSE). Elevations in other parameters like systolic pulmonary arterial pressure, mean pulmonary arterial pressure, and pulmonary vascular resistance (PVR) were inconsistent. Most of the patients with arrhythmias suffered symptoms and improved after sinus rhythm (SR) was restored. The prognostic relevance of nonsustained ventricular tachycardia was evaluated in only one study. Non-sustained ventricular tachycardia does not seem to be prognostically relevant. Extending Holter electrocardiogram (ECG) monitoring over 24 hours up to 72 hours raises the detection rate of arrhythmias. Ablation of arrhythmias, especially atrial flutter and atrioventricular node reentry tachycardia, is feasible and safe in these patients.

Keywords: Pulmonary Hypertension, Arrhythmias, Atrial Flutter, Atrial Fibirllation, Prognostic Relevance
\end{abstract}

\section{Background}

Pulmonary hypertension $(\mathrm{PH})$ is defined as an increase in the mean pulmonary pressure (mPAP) $>25 \mathrm{~mm} \mathrm{Hg}$ at rest and capillary wedge pressure (PCWP) $<15 \mathrm{~mm}$ $\mathrm{Hg}$ in precapillary (group 1,3-5) or $>15 \mathrm{~mm} \mathrm{Hg}$ in postcapillary (group 2) forms. ${ }^{1}$ Proliferation of pulmonary artery smooth muscle and endothelial cells, endothelial dysfunction, inflammation and excessive vasoconstriction lead to arteriolar obstruction, elevated pulmonary arterial pressure, and increased pulmonary vascular resistance (PVR). ${ }^{2,3}$ Increased PVR causes elevated afterload of the right ventricle and cardiac remodelling. ${ }^{4}$ Elevated rightsided filling pressure and cardiac remodelling could provide the substrate or trigger for arrhythmias. ${ }^{5,6}$ Several studies have evaluated the incidence of supraventricular and ventricular arrhythmias and their prognostical relevance in patients with $\mathrm{PH} .^{7-15}$

It is already known that supraventricular arrhythmias are associated with clinical deterioration, but the incidence of sudden cardiac death was not elevated in these patients..$^{8,10,12,14,15}$ The incidence and clinical/prognostical relevance of non-sustained ventricular tachycardia was analyzed in only three studies. ${ }^{16-18}$

\section{Objective}

The aim of this review is to give an actual and comprehensive overview of the current literature with respect to incidence and clinical and prognostical relevance of arrhythmias in patients with $\mathrm{PH}$.

\section{Methods}

This review summarized the current evidence from the literature. Studies indexed (until 20/11/2017) in Medline and published in English or German that investigated patients in all $\mathrm{PH}$ groups (1-5) were considered. Medline searches included the following keywords: pulmonary hypertension, $\mathrm{PH}$, incidence, arrhythmias, supraventricular arrhythmias, ventricular arrhythmias, ventricular

Copyright $\odot 2018$ The Author(s). This is an open-access article distributed under the terms of the Creative Commons Attribution License (http:// creativecommons.org/licenses/by/4.0), which permits unrestricted use, distribution, and reproduction in any medium, provided the original work is properly cited. 
tachycardia, atrial fibrillation, atrial flutter, prognostic relevance, electrophysiological studies, ep-studies, EPS, and ablation. Studies fulfilling the search criteria were reviewed for incidence of arrhythmia, diagnostic tools, kinds of arrhythmia, patient characteristics, correlation of echocardiographic results/hemodynamic parameters and arrhythmias, clinical relevance of arrhythmias, and prognostic relevance of arrhythmias.

\section{Results}

\subsection{Supraventricular Arrhythmias}

Supraventricular arrhythmias in patients with $\mathrm{PH}$ were evaluated in nine studies (Table 1).
In a recent study by the current authors, 167 patients (mean age $61.5 \pm 14.4$ years) with an initial diagnosis of $\mathrm{PH}$ (groups 1-5) were evaluated for incidence of arrhythmia during long-term follow up (FU), and the prognostic value of electrocardiography data was assessed. ${ }^{7}$ Baseline electrocardiograms (ECGs) revealed a sinus rhythm (SR) in 137 patients and atrial fibrillation (AFib) in 30 patients, most of whom suffered from pulmonary venous hypertension (PVH, 53.3\%). During follow up $(n=137$ patients), AFib was detected in 13 patients (53.8\% group 1 $\mathrm{PH})$. At the timepoint of baseline ECG, patients were treated with beta-blockers $(n=42)$, calcium channel blockers $(\mathrm{n}=35)$, and digitalis $(\mathrm{n}=13)$, and a cardiac pacemaker was

Table 1. Studies Investigating Supraventriuclar Arrhythmias in Patients With Pulmonary Hypertension

\begin{tabular}{lllllll}
\hline First Author & Year & $\begin{array}{l}\text { No. of } \\
\text { Patients }\end{array}$ & $\begin{array}{l}\text { PH } \\
\text { Group(s) }\end{array}$ & Arrhythmias & $\begin{array}{l}\text { Diagnostic } \\
\text { Tool }\end{array}$ & Main Results \\
\hline Bandorski ${ }^{7}$ & 2016 & 167 & $1-5$ & AFib & 12-lead ECG $\begin{array}{l}\text { Retrospective study; elevated right atrial diameter/ } \\
\text { pressure in patients with AFib }\end{array}$
\end{tabular}

$\begin{array}{lllll}\begin{array}{l}\text { Malaczynska- } \\ \text { Rajpold }^{8}\end{array} & 2015 & 48 & 1 & \text { AFib, AFlu, AT, fVT }\end{array}$

Retrospective study; elevated right atrial diameter/ pressure/BNP and lower TAPSE in patients with

12-lead ECG arrhythmias, survival in patients with/without arrhythmias $(41.9 \%$ vs. $66.3 \%$; not statistically significant)

$\begin{array}{llll} & & \text { AFib, ectopic atrial } \\ & & & \\ \text { Cannillo } & & \text { tacycardia, right atrial } \\ & \text { flutter, AVNRT, paroxysmal } & \text { supraventricular tachycardia }\end{array}$
Retrospective study; elevated NT-proBNP in
12-lead ECG patients with arrhythmia, no differences in right atrial parameters, mortality higher in patients with arrhythmias (53\% vs. $13 \%$ )

Prospective study; survival in patients with transient episodes of arrhythmia not statistically different from patients without arrhythmias, shorter

$\begin{array}{lllll}\text { Wen }^{10} & 2014 & 280 & 1 & \text { AFib, AFlu, AT }\end{array}$

12-lead ECG survival in patients with permanent arrhythmias, elevated right atrial and ventricle diameter/ pressure/BNP, and reduced $\mathrm{Cl}$, mixed venous saturation in patients with arrhythmias

\begin{tabular}{|c|c|c|c|c|c|c|}
\hline Kamanthareddy ${ }^{11}$ & 2014 & 311 & $1-5$ & AFib, AFlu & 12-lead ECG & $\begin{array}{l}\text { Retrospective study; many patients with group } \\
2 \mathrm{PH}(69.4 \%) \text {, no prognostic relevance of } \\
\text { arrhythmias, high rate of recurrence after ablation } \\
\text { and high rate of new onset (other) of arrhythmia }\end{array}$ \\
\hline Olsson $^{12}$ & 2014 & 239 & 1,4 & AFib, AFlu & 12-lead ECG & $\begin{array}{l}\text { Prospective study; survival in patients with } \\
\text { transient episodes of arrhythmias not statistically } \\
\text { different from patients without arrhythmias, } \\
6 \text {-MWD reduced+BNP elevated during arrhythmia } \\
\text { and increased/decreased after restoration of SR, } \\
\text { baseline values of RAP, mPAP and PVR higher in } \\
\text { patients with arrhythmias }\end{array}$ \\
\hline Rottlaender ${ }^{13}$ & 2012 & 225 & $1-5$ & AFib & 12-lead ECG & $\begin{array}{l}\text { Retrospective study; NT-proBNP elevated and } \\
6-\mathrm{MWD} \text { reduced in patients with arrhythmias, } \\
\text { right atrial pressure/ right atrial area elevated and } \\
\text { TAPSE/cardiac output reduced in patients with } \\
\text { arrhythmias }\end{array}$ \\
\hline Ruiz-Cano ${ }^{14}$ & 2010 & & & & $\begin{array}{l}\text { 12-lead } \\
\text { ECG, EPS }\end{array}$ & $\begin{array}{l}\text { Retrospective study; arrhythmias led to clinical } \\
\text { relevant restoration of SR, improved 6-MWD, } \\
\text { ablation (AVNRT/Aflu) effective and safe }\end{array}$ \\
\hline Tongers $^{15}$ & 2007 & 231 & & & 12-lead ECG & $\begin{array}{l}\text { Retrospective study, arrhythmias led to clinical } \\
\text { detetoriation, higher mortality in patients with } \\
\text { arrhythmias }\end{array}$ \\
\hline
\end{tabular}

$\mathrm{AFib}=$ atrial fibrillation, AFlu=atrial flutter, AT=atrial tachycardia, ECG=electrocardiogram, EPS=electrophysiological study, $\mathrm{fVT}=\mathrm{fascicular}$ ventricular tachycardia, $\mathrm{mPAP}=$ mean pulmonary arterial pressure, $\mathrm{No}=\mathrm{Number}, \mathrm{PVR}=$ pulmonary vascular resistance, $\mathrm{PH}=$ pulmonary hypertension, $\mathrm{RAP}=\mathrm{right}$ atrial pressure, $\mathrm{SR}=$ sinus rhythm, $6-\mathrm{MWD}=$ six minute walk distance. 
implanted in 17 patients (indication: bradyarrhythmia). In patients developing AFib during follow up, P-wave duration was not different from that in patients with SR $(0.11 \pm 0.02$ s vs. $0.10 \pm 0.02$ seconds; $P=0.193)$. Patients with short $\mathrm{P}$-waves $(<0.1 \mathrm{~s})$ showed improved survial rates (88.1 \pm 6.7 vs. $49 \pm 5.8$ months) compared to patients with long P-waves (>0.11 s), considering that this association was influenced by age (multivariate analysis). Other ECG parameters showed no correlation between duration of intervals and survival. Survival from diagnosis was $79.4 \pm 5.4$ months in patients with SR, 64.4 \pm 12.9 months in patients with AFib during FU, and $58.8 \pm 8.9$ months in patients with $\mathrm{AFb}$ in baseline ECG $(P=0.565)$. Patients with AFib had higher atrial diameter, atrial pressure and reduced tricuspid annular plane systolic excursion (TAPSE) without statistical significance.

Malaczynska-Rajpold et al investigated the prevalence and type of arrhythmias and the efficiency/safety of antiarrhythmic treatment over a follow-up period of $28.8 \pm 17.7$ months in 48 patients with group $1 \mathrm{PH}^{8}$ Seventeen patients suffered from arrhythmias like AFib $(\mathrm{n}=8)$, atrial tachycardia $(\mathrm{AT}, \mathrm{n}=6)$, and atrial flutter (AFlu, $n=6$ ). Four patients had more than one type of tachyarrhythmia. One patient with a fascicular ventricular tachycardia was not included in the statistical analysis. Patients with arrhythmias were older (52.4 \pm 15.3 vs. $47.4 \pm 16.5$ years, $P>0.05)$, NT-proBNP was higher $(2658.9 \pm 3020.3$ vs. $1748.0 \pm 1646.5 \mathrm{pg} / \mathrm{mL})$, and hemodynamic measurement/echocardiography revealed higher right atrial pressure $(11.6 \pm 3.8$ vs. $7.1 \pm 3.6 \mathrm{~mm}$ $\mathrm{Hg} ; P>0.05)$, right atrial area $(33.4 \pm 12.3$ vs. $25.8 \pm 6.3$ $\mathrm{mm}^{2} ; P=0.01$ ), pericardial effusion ( 53 vs. $16 \% ; P=0.008$ ), and lower TAPSE $(14.4 \pm 4.6$ vs. $18.4 \pm 5.7 \mathrm{~mm} ; P=0.02)$. More than half of the arrhythmic episodes (59\%) led to clinical deterioration and/or right heart failure (functional class, edema of the lower extremities, ascites) with a recurrence of the same or another arrhythmia within $5.3 \pm 3.4$ months. Treatment of arrhythmia included direct current cardioversion/overdrive pacing (AFlu, AFib, and AT), medical treatment with amiodarone, propafenone or verapamil (AFib) and radiofrequency ablation (AFlu, AT) in 10 of 17 patients. Six-year survival rates were $41.9 \%$ vs. $66.3 \%$ in patients with arrhythmias vs. patients without arrhythmias $(P=0.64)$.

Cannillo et al revealed Afib (paroxysmal: $\mathrm{n}=1$, persistent: $\mathrm{n}=8$, permament: $\mathrm{n}=3$ ), ectopic atrial tachycardia $(\mathrm{n}=2)$, right atrial flutter $(\mathrm{n}=2)$, atrioventricular node reentry tachycardia (AVNRT, $\mathrm{n}=1$ ), and paroxysmal supraventricular tachycardia during a follow-up period of 35 months [IQR 21.5 to 53.5] in their patients (mean age $=66.7$ years). ${ }^{9}$ Detection of arrhythmias occurred during either routine follow up $(n=4)$ or symptom-related diagnostic treatment $(n=13)$ in mean 15.1 months [IQR 11.3 to 43.2 ] after the initial diagnosis of PH. Patients with/ without arrhythmias showed no significant differences. The only difference was that NT-proBNP was lower in patients without arrhythmias (795 vs. $1370 \mathrm{pg} / \mathrm{mL}$ ) without statistical significance $(P=0.48)$. Treatment of arrhythmias involved rhythm control strategy $(n=13$, amiodarone, sotalol, Ic antiarrhythmic drugs), electrical cardioversion $(n=8)$, and radiofrequency ablation $(n=3$, AVNRT/AFlu/AFib+AFlu). SR was initially restored in 11 patients. Recurrence of arrhythmia $(n=9)$ led to clinical deterioration associated with worsening of WHO functional class, reductions in the 6-minute walk and TAPSE, and higher levels of NT-proBNP. Mortality was higher in patients with arrhythmias (53\% vs. $13 \%$; $\mathrm{p}=0.001$ ). Mean time between occurrence of arrhythmia and death was 3.5 months [IQR 1.7 to 9.1].

Another study investigated 280 patients (mean age $39 \pm 15$ years) with group $1 \mathrm{PH}$ and SR. ${ }^{10}$ ECGs revealed AFib $(n=16)$, AFlu $(n=13)$, and AT $(n=11)$ with an incidence of $6.4 \%, 12.4 \%$, and $15.8 \%$ during the first, third, and sixth years of follow up ( $31 \pm 7$ months). Survival was lower in patients with arrhythmias (estimated survival at 1,3 , and 6 years was $85 \%, 64 \%$, and $53 \%$ vs. $92 \%, 82 \%$, and $75 \%, P=0.008$ ), whereas survival was better in patients with transient episodes of arrhythmia than in patients with permanent arrhythmias $(P=0.011)$ and statistically not different from patients without arrhythmias $(P=0.850)$. Arrhythmias led to clinical symptoms like dyspnea, palpitations, edema, or worsening of WHO functional class. Under therapy (electrical cardioversion, $\mathrm{n}=2$; radiofrequency ablation, $\mathrm{n}=1$; antiarrhythmic drugs, $\mathrm{n}=37$ ), all patients converted to SR leading to clinical improvement. Recurrence of arrhythmia was observed in 7 of 13 patients with and in 12 of 16 patients with AFib. In patients with arrhythmias, echocardiogaphy revealed high rates of dilated right atria and ventricles and pericardial effusions. Right atrial pressure ( $13 \pm 5$ vs. $8 \pm 5 \mathrm{~mm} \mathrm{Hg})$ and PVR ( $18 \pm 7$ vs. $15 \pm 7$ Wood units) were higher, and the cardiac index $\left(2.3 \pm 0.9\right.$ vs. $\left.2.6 \pm 1.51 / \mathrm{min} / \mathrm{m}^{2}\right)$ and mixed venous saturation $(59 \pm 9 \%$ vs. $62 \pm 11 \%)$ were lower in patients with arrhythmias. BNP was elevated (456 \pm 396 vs. $318 \pm 339 \mathrm{pg} / \mathrm{mL} ; P=0, .007)$ in these patients, too.

The study of Kanmanthareddy et al investigated the incidence of arrhythmias in 311 patients (mean age $61 \pm 13$ years) with all groups of $\mathrm{PH}$; most of them (69.4\%) suffered group $2 \mathrm{PH} .{ }^{11}$ ECGs revealed AFib or AFlu in 121 patients (39\%). The authors did not give any information about the distribution of arrhythmias related to $\mathrm{PH}$ groups. Patients with arrhythmias were older $(66 \pm 12$ vs. $57 \pm 14$ years; $P<0.001)$ and suffered from arterial hypertension more often ( $74 \%$ vs. $67 \% ; P=0.03)$, diabetes $(38 \%$ vs. $30 \% ; P=0.015)$, coronary artery disease $(59 \%$ vs. $55 \%$; $P<0.001$ ), mitral regurgitation (79 vs. 57\%); $P=0.001$ ), and impaired left ventricular ejection fraction (LV-EF $<50 \%)(28 \%$ vs. $17 \%$; $P=0.027)$. Pulmonary capillary wedge pressure (PcWP) was higher $(20.3 \pm 8$ vs. $17 \pm 9 \mathrm{~mm}$ $\mathrm{Hg} ; P=0.022)$ and left atrium was more dilated $(4.7 \pm 0.9$ vs. $4 \pm 0.7 \mathrm{~mm} ; P<0.001)$ in patients with arrhythmias. Age (OR 1.04; $P=0.04)$ and left atrial size $(2.57 ; P<0.001)$ were independent predictors of mortality in multivariate regression analysis. During follow up (22 \pm 14 months), 
35 patients (12\%) died; no significant difference was observed between patients with and without arrhythmias (10\% and 13\%, respectively; $P=0.549$ ). Forty-three patients underwent ablation: 20 patients with cavotricuspid isthmus ablation for right atrial flutter, 10 patients pulmonary vein isolation for AFib (additional cavo-tricuspid isthmus ablation $\mathrm{n}=4$ ), and 13 patients atrioventricular node ablation. One year after ablation, $17 / 20$ patients who underwent cavo-tricuspid isthmus ablation developed AFib, and all patients after pulmonary vein isolation had a recurrence of AFib.

Olsson and colleagues study investigated 231 patients (mean age 55 years) with $\mathrm{PH}$ (group 1: 157 patients, group 4 (inoperable chronic thromboembolic $\mathrm{PH}$ ): 82 patients]. ${ }^{12}$ Arrhythmias were detected in 48 patients, AFib and AFlu in 24 patients each. Patients who developed arrhythmias during follow up had higher baseline values for right atrial pressure ( 8 vs. $6 \mathrm{~mm} \mathrm{Hg} P=0.035$ ), mean pulmonary arterial pressure (52 vs. $45 \mathrm{~mm} \mathrm{Hg} P<0.001)$, PVR (880 vs. 700 dyn s cm ${ }^{-5} ; P<0.001$ ), NT-proBNP (3340 vs. 2113 ng/L; $P=0.394)$, and lower values for cardiac index $(2.3$ vs. $\left.2.5 \mathrm{l} / \mathrm{min} / \mathrm{m}^{2} ; P=0.213\right)$ and mixed venous saturation (60 vs. $64 \% ; P=0.002$ ). Patients with group $1 \mathrm{PH}$ seemed to be more at risk to develop arrhythmias. Incidence for new onset of an arrhythmia after 1, 2, 3 and 4 years was $13.4 \%, 9.2 \%, 23.6 \%$, and $25.1 \%$, respectively. Patients with arrhythmia presented with dyspnea on exertion, weight gain $(>2 \mathrm{~kg})$, palpitations, worsening of functional class, right heart failure, and increased heart rate with a mean of 112 beats/min, 33 beats/min higher than before onset of arrhythmia. Only 17\% of patients were without symptoms and in clinical stable condition. Distance in 6-MW shortened during episodes of arrhythmia (before: $362 \pm 114 \mathrm{~m}$; after detection of arrhythmia: $258 \pm 147 \mathrm{~m}$; at follow up: $345 \pm 137 \mathrm{~m} ; P<0.05$ ). BNP (baseline level $2687 \pm 2260 \mathrm{ng} / \mathrm{L})$ significantly increased $(P<0.05)$ with onset of arrhythmia (5926 $\pm 4648 \mathrm{ng} / \mathrm{L})$ and decreased after restoration of SR $(3360 \pm 2804 \mathrm{ng} / \mathrm{L})$. SR was initially restored in all patients with AFlu (electrical cardioversion $\mathrm{n}=9$, overdrive pacing $\mathrm{n}=1$, radiofrequency ablation $\mathrm{n}=3$, drug therapy $n=11$ ) and in 16 patients with AFib (drug therapy: amiodarone $\mathrm{n}=2$, dronedarone $\mathrm{n}=1$; electrical cardioversion $n=18$ ). Survival in patients with arrhythmias was shortened in comparison to patients without arrhythmias ( $1 / 2 / 3$ years: $87 \% / 82 \% / 76 \%$ vs. $91 \% / 81 \% / 55 \%$; $P=0.037)$. Patients with AFib had a higher mortality than patients with AFib ( $1 / 2 / 3$ years: $82 \% / 77 \% / 69 \%$ vs. $89 \% / 86 \% / 79 \% ; P=0.042$ ), whereas survival in patients with paroxysmal episodes of arrhythmias was not significantly different from patients without arrhythmias ( $1 / 2 / 3$ years: $96 \% / 90 \% / 69 \%$ vs. $87 \% / 82 \% / 76 \% ; P=0.039)$. Restoration of SR was prognostically relevant. Patients who developed permanent AFib had a shorter survival period than patients in whom SR was restored $(1 / 2 / 3$ years: $64 \% / 55 \% / 27 \%$ vs. $95 \% / 80 \% / 57 \% ; P=0.01$ ).

Rottlaender et al investigated the incidence of AFib in 225 patients (age: SR 62.9 \pm 1.2 , AFib 71.2 \pm 1.1 ) with $\mathrm{PH}$ of all groups. ${ }^{13}$ Many patients $(\mathrm{n}=52)$ suffered from group $2 \mathrm{PH}(42.9 \%)$. AFib was detected in 70 patients $(31.1 \%)$, paroxysmal AFib in 29 patients (41.3\%), and permanent/ persistant AFib in 41 patients (58.7\%). Most patients with AFib had either group 2 (42.9\%) or group 4 (20\%) PH and suffered from coronary heart disease $(27.1 \%)$ and arterial hypertension (63.3\%). NT-proBNP was elevated in patients (all $\mathrm{PH}$ groups) with AFib (2128.88 \pm 429.97 vs. $3252.79 \pm 401.76 ; P<0.05)$ and the 6 -minute walk distance (6-MWD) was shorter $(355.55 \pm 9.86$ vs. $321.98 \pm 14.1$; $P<0.05)$. Excluding patients with group $2 \mathrm{PH}$ showed similar trends related to NT-proBNP and 6-MWD. Hemodynamic and echocardiogaphic evaluation revealed elevated right atrial pressure and right atrial area and reduced values of TAPSE and cardiac output.

Ruiz-Cano et al evaluated the clinical implications of arrhythmias in patients with $\mathrm{PH}$ (group 1) and assessed the safety and effiacy of electrophysiological studies (EPS) in these patients $(n=282$, mean age $47.3 \pm 14.3$ years $) .{ }^{14}$ Mean interval between diagnosis of $\mathrm{PH}$ and onset of arrhythmia was $60.3 \pm 55.9$ months. Number of detected arrhythmias was 28 (AFib in 12 patients, AFlu in 12 patients and ANVRT in 4 patients). Most of the patients (AFib, AFlu, but not AVNRT) suffered from symptoms (82\%), and 6-MWD decreased from $423.7 \pm 74.6$ to $252.1 \pm 145.8 \mathrm{~m}$ $(P<0.001)$ after onset of arrhythmia. Conversion to SR led to an increased distance in the 6-MWD of $196 \pm 163$ m. Approximately half $(46.4 \%)$ of the patients needed an increase in $\mathrm{PH}$-specific therapy independent from conversion to SR or rate control. Mean time from onset of arrhythmia to death or transplantation was 17.8 months. Five patients (AFib N01, AFlu n=4) died during follow up. Ablation was effective in all patients with AVNRT and in most patients with AFlu (95\%).

Tongers et al performed the first evaluation of incidence and clinical relevance of arrhythmias in patients with $\mathrm{PH}(\mathrm{n}=231)$ [group 1: 204 patients; group 4 (inoperable chronic thromboembolic $\mathrm{PH}): 27$ patients]. ${ }^{15}$ Arrhythmias were observed in 27 patients (AFib $n=12$, AFlu $n=12$, AVNRT $n=3)$ in an average of 3.5 years $(0 \pm 238$ months $)$ after the initial diagnosis of PH. Most episodes (84\%) led to clinical deterioration (worsening of functional class, edema, refractory ascites). Treatment of arrhythmias included cardioversion (AFib $n=6$, AFlu $n=2$ ), overdrive pacing (AFlu $n=3$ ), ablation (AFlu $n=5$, AVNRT $n=4$ ), and medical treament with amiodarone, verapamil, digoxin, and beta-blockers. Four patients suffered from a recurrence of arrhythmia: one patient after cavo-tricuspid isthmus ablation for AFlu, one patient after overdrive pacing for AFlu, and 2 patients after ablation of AVNRT. Restoration of SR improved clinical symptoms, and these patients had a markedly lower mortality than those without SR restoration $(6.3 \%$ vs. $81 \%, P=0.01)$.

\subsection{Ventricular Arrhythmias}

Only a few studies have evaluated the incidence and clinical relevance of non-sustained ventricular tachycardia in 
Table 2. Studies Investigating Ventricular Arrhythmias in Patients With Pulmonary Hypertension

\begin{tabular}{|c|c|c|c|c|c|c|}
\hline First Author & Year & $\begin{array}{l}\text { No. of } \\
\text { Patients }\end{array}$ & PH-Group(s) & Arrhythmias & Diagnostic Tool & Main Results \\
\hline Bandorski ${ }^{16}$ & 2016 & 78 & 1,4 & ns-VT & $\begin{array}{l}\text { Holter-ECG 24- } \\
72 \mathrm{~h}\end{array}$ & $\begin{array}{l}\text { Retrospective study; first evaluation of } \\
\text { prgonostic relevance of ns-VT, ns-VT not } \\
\text { prognostically relevant, TAPSE reduced in } \\
\text { patients with ns-VT, no difference in mean } \\
\text { atrial pressure }\end{array}$ \\
\hline Bandorski ${ }^{17}$ & 2015 & 92 & $1,3-5$ & $\begin{array}{l}\text { AFlu, ns-VT, second-degree } \\
\text { heart block, third-degree } \\
\text { heart block, non-sustained } \\
\text { artial tachycardia }\end{array}$ & $\begin{array}{l}\text { Holter-ECG for } \\
72 \text { h during daily } \\
\text { activity }\end{array}$ & $\begin{array}{l}\text { Prospective study; first time Holter-ECG } \\
\text { during daily activity, ns-VT in } 13 \% \text {, reduced } \\
\text { TAPSE/CI/venous saturation and elevated } \\
\text { PVR in patients with ns-VT/AFlu/heart } \\
\text { blocks }\end{array}$ \\
\hline Folino $^{18}$ & 2003 & 9 & 1 & PVC & $\begin{array}{l}\text { Holter-ECG for } \\
24 \mathrm{~h}\end{array}$ & $\begin{array}{l}\text { PVC }>700 / 24 \mathrm{~h} \text { in } 4 \text { patients, } \\
\text { SDNN+SDANN reduced in patients with } \\
\text { higher RVSP }\end{array}$ \\
\hline
\end{tabular}

AFlu=atrial flutter, ECG=electrocardiogram, $\mathrm{No}=$ number, $\mathrm{ns}-\mathrm{VT}=$ non-sustained ventricular tachycardia, $\mathrm{PVC}=$ premature ventricular complexes, $\mathrm{RVSP}=$ right ventricular systolic pressure, SDNN=standard deviation (SD) of all NN (N: normal) intervals, SDANN SD of the averages of $\mathrm{NN}$ intervals in 5-min segments.

patients with $\mathrm{PH}$ (Table 2). ${ }^{16-18}$ Bandorski et al investigated 92 patients with $\mathrm{PH}$ (groups 1, 3-5) without a known history of preexisting arrhythmias. ${ }^{17}$ Functional class was NYHA III/IV in $70.6 \%$. Because of arterial hypertension, 13 patients were treated with beta-blockers. All 65 patients underwent Holter-ECG monitoring over 72 hours during daily activity, and mean recording time was 64 hours and 9 minutes. Heart rate ranged from 56 beats/min to 124 beats/ min. Relevant arrhythmias were detected in 17 patients, non-sustained ventricular tachycardia (ns-VT, length 3-20 beats, cycle length: $260-600 \mathrm{~ms}, \mathrm{n}=12$ ), intermittent second-degree heart block, and intermittent third-degree heart block $(n=3)$ and AFlu $(n=1)$. Most cases of ns-VT (58.3\%) were observed between 24 hours and 48 hours of Holter-ECG monitoring, and 25\% was seen within the first 24 hours of monitoring. The other arrhythmias were also detected during the first 24 hours. Underlying etiologies were $\mathrm{PH}$ of groups 1, 4, and 5 (53\%, 41\%, and $16 \%)$ in patients with ns-VT, group $1 \mathrm{PH}$ in AFlu, group $4 \mathrm{PH}$ in intermittent second-degree heart block, and $\mathrm{PH}$ of groups 1 and 4 in intermittent third-degree heart block. None of the patients suffered from an LV-EF $<50 \%$, and coronary heart disease was known in 3 patients (AFlu: $\mathrm{n}=1$, ns-VT: $\mathrm{n}=2$ ). Two patients with third-degree heart block underwent cardiac pacemaker implantation. In one patient, the beta-blocker application was interrupted, and Holter-ECG did not show heart blocks anymore. One patient with second-degree heart block declined cardiac pacemaker implantation. Holter ECG revealed nonsustained atrial tachycardia. SDNN was lower in patients with AFlu, heart blocks, and ns-VT (129.29 ms vs 139.39 $\mathrm{ms} ; \mathrm{P}=0.008)$. Holter ECG revealed $70 \mathrm{VES} / 72 \mathrm{~h}(0-15946)$ on average and 85 SEVS/72 h (0-13,622). BNP levels were higher in patients with AFlu, heart blocks, and ns-VT (198.47 vs. $91.73 \mathrm{pg} / \mathrm{mL} ; P=0.04$ ). Echocardiography and hemoydnamic monitoring showed reduced TAPSE (19.2 vs. $21.4 \mathrm{~mm} ; P=0.95)$, CI (2.46 vs. $2.82 \mathrm{~L} / \mathrm{min} / \mathrm{m}^{2}$; $P=0.158)$, venous oxygen saturation $(64.67 \%$ vs. $68.41 \%$; $P=0.158$ ), and elevated PVR (542 vs. 672 dyn.s.cm ${ }^{-5}$; $P=0.247)$ in patients with AFlu, heart blocks, and ns-VT.
The prognostic relevance of ns-VT was not evaluated in this study. The survival of patients with ns-VT from 2 of the authors' studies was investigated retrospectively. ${ }^{16}$ To match the results with other studies, only patients $(n=78)$ with $\mathrm{PH}$ of groups 1 and 4 were included. Holter-ECG revealed ns-VT in 12 patients ( $\mathrm{PH}$ group $1: \mathrm{n}=8$, group 4: $\mathrm{n}=4$ ). Mean time from first diagnosis of $\mathrm{PH}$ to Holter ECG was $6.2 \pm 4.1$ years in patients with ns-VT vs. $5.4 \pm 3.9$ years in patients without ns-VT $(P=0.736)$. Patients with ns-VT were older $(66.6 \pm 12.4$ vs. $60 \pm 14.7$ years; $p=0.112)$ and had shorter 6-MWD $(283 \pm 109$ vs. $387 \pm 281 ; P=0.941)$. Echocardiography revealed reduced TAPSE (15.7 vs. 20.9 $\mathrm{mm} ; \mathrm{p}=0.001)$ and elevated systolic pulmonary arterial pressure (sPAP, 72.7 vs. $61.6 \mathrm{~mm} \mathrm{Hg} P=0.163$ ) in patients with ns-VT. Results of right heart catheterization showed higher mean pulmonary arterial pressure (mPAP, 47.7 vs. $40.2 \mathrm{~mm} \mathrm{Hg} ;=0.865$ ), PVR (835 vs. 532 dyn.s.cm ${ }^{-5}$; $P=0.353$ ), and reduced cardiac index ( 2.42 vs. $2,81 \mathrm{l} / \mathrm{min} /$ $\left.\mathrm{m}^{2} ; P=0.390\right)$ and venous saturation ( 64 vs $\left.685 ; P=0.700\right)$ in patients with ns-VT. Interval from first diagnosis to death was not significantly different $(P=0.855)$ between patients with and without ns-VT $(7.9 \pm 3.5$ vs. $8.4 \pm 3.9$ years). Mean atrial pressure was not different in patients with and without ns-VT (4.3 vs. $4.4 \mathrm{~mm} \mathrm{Hg} P=0.865$ ).

Folino and colleagues' study evaluated ventricular arrhythmias and autonomic profiles in patients $(n=9)$ with group $1 \mathrm{PH}$ using $24 \mathrm{~h}$ Holter ECG monitoring. ${ }^{18}$ In all patients, LV-EF was $>50 \%$ (mean $65.2 \pm 6$ ), values of RV-EF were between $44 \%-55 \%$ (mean $49.3 \pm 5 \%$ ), and right ventrIcular systolic pressure (RVSP) of $91.2 \pm 25 \mathrm{~mm}$ $\mathrm{Hg}$. Three patients had an anamnesis of syncope. Holter ECG showed premature ventricular complexes (PVC, $>700 / 24 \mathrm{~h}$ ) in 4 patients and couplets in 2 patients. SDNN and SDANN were reduced in comparison to a control group of twenty healthy subjects (age $39 \pm 18$ years) and in patients with PVC $>700 / 24 \mathrm{~h}$. Cardiopulmonary exercise tests revealed reduced workloads in all patients. Reasons for discontinuation were dyspnea and physical exhaustion; ventricular arrhythmias were recorded in none of the patients. Patients with the lowest SDNN (<90 ms) showed 
higher RVSP $(115 \pm 22.9$ vs. $79.2 \pm 17.8 \mathrm{~mm} \mathrm{Hg} ; P<0.05)$. SDNN was elevated in patients with syncope $(131.7 \pm 36.5$ vs. $88.4 \pm .20 .0)$.

\section{Discussion}

Incidence of supraventricular arrhythmias varied between $7.8 \%$ and $35 \%^{7-15}$; reasons for this difference remain unclear. Age does not seem to be a reason, because in the authors' study, ${ }^{7}$ patients were older and had lower incidence of arrhythmias than in other studies, ${ }^{8-15}$ despite it being well-known that prevalance of AFib increases with age. ${ }^{19}$ Patients underwent (only) repeated twelve-lead ECGs in all studies during follow up. Self limiting episodes of arrhythmias may have been missed.

It is noteworthy that TAPSE was reduced, ${ }^{7,8,13}$ and $\mathrm{BNP},{ }^{12,13}$ right atrial area, ${ }^{7,8,10,13}$ and mean right atrial pressure ${ }^{7,8,10,13}$ were elevated in patients with arrhythmias. In Olsson and colleagues' study, all patients had normal left atrial dimensions ${ }^{12}$; in Rottlaender and colleagues' study, in patients without group $2 \mathrm{PH}$, elevated right atrial pressure and right atrial dilatation were associated with $\mathrm{Afib}^{13}$ and seemed to be responsible for it.

Studies have revealed that supraventricular arrhythmias are prognostically relevant. ${ }^{7-9,12}$ Interestingly, in the studies of Wen and Olsson, survival in patients with transient episodes of arrhythmias was not statistically different from patients without arrhythmias. ${ }^{10,12}$ Most patients with arrhythmias suffered from symptoms $s^{8-10,14}$ and improved after restoration of SR. ${ }^{8,12}$ In Olsson and colleagues' study, restoration of SR was associated with improved 6-MWD and decreased NT-proBNP. ${ }^{12}$ Interestingly, in Ruiz-Cano and colleagues' study, $46.4 \%$ of the patients needed more specific treatment of $\mathrm{PH}$ despite the restoration of SR or control of ventricular rate. ${ }^{14}$

Few studies have evaluated the prognostic relevance of ECG parameters. P-wave duration was associated with shorter survival, but in multivariate analysis this association was only borderline significant when age was included as a covariate $(P=0.06) .{ }^{7}$ QRS-width ${ }^{19}$ and duration of QTinterval ${ }^{20,21}$ were assessed in patients with $\mathrm{PH}$ and showed correlations with mortality. The results of these studies were not reported in other studies.

Ventricular tachycardias in patients with $\mathrm{PH}$ were revealed during continuous monitoring with HolterECG. ${ }^{16,17}$ In accordance with the results of studies evaluating supraventricular arrhythmias, TAPSE was reduced in patients with $n s \mathrm{VT}^{16,17}$ and cardiac index was reduced, whereas PVR, sPAP, and mPAP were elevated. ${ }^{16,17}$ The authors' study showed that extending Holter ECG monitoring to longer than 24 hours raised the detection rate of arrhythmias. ${ }^{17}$ The main result of the study was that the prognostical relevance of nsVT was missing. Because of the moderate sample size, the prognostic relevance and risk factors for nsVTs need to be obtained in larger series.

Electrophysiological studies showed that ablation in patients with AFlu is feasible and safe. ${ }^{21-27}$ In Medi and colleagues' study, patients with right atria showing
Review Highlights

\section{What Is Already Known?}

Supraventricular arrhythmias are common in patients with pulmonary hypertension and lead in most cases to clinical deterioration. If possible cardioversion should be obtained. Permanent arrhythmias are associated with a worse prognosis.

\section{What This Study Adds?}

This review highlights the frequency of (non-sustained) ventricular arrhythmias in patients with pulmonary hypertension and their prognostical relevance. Rhythm control should be sought in patients with supraventricular arrhythmias. Another important information is extending of Holter ECG monitoring ( $>24$ hours) to raise the detection rate of arrhythmias. In patients with atrial flutter, focal atrial tachycardia and atrioventricular nodal reentrant tachycardia ablation is feasible and safe.

reduction of conduction velocity and an increase of areas of low voltage or electrical silence due to interstitial fibrosis were found. ${ }^{24}$ The authors discussed these findings as a reason for lower pharmacologic or catheter-based success to restore $\mathrm{SR}{ }^{24}$

\section{Conclusion}

Supraventriuclar arrhythmias are common and, except transient forms, prognostically relevant in patients with $\mathrm{PH}$. Most patients suffer from clinical symptoms. Restoration of SR should be targeted to improve patients clinical presentation. Elevated RAP and right atrial diameters and reduced TAPSE are risk factors. The relevance of ECG parameters has to be evaluted in further studies. Nonsustained ventricular tachycardias showed no prognostical relevance in one study. Ablation of arrhythmias is feasible and safe.

\section{Authors' Contributions}

Both authors fulfill the following International Committee of Medical Journal Editors (ICMJE) criteria for authorship: 1. Substantial contributions to the conception and design of the study or the acquisition, analysis, or interpretation of the data;

2. Drafting of the article or critical revision for important intellectual content;

3. Final approval of the version to be published;

4. Agreement to be accountable for all aspects of the work in ensuring that questions related to the accuracy or integrity of any part of the article are appropriately investigated and resolved.

\section{Conflict of Interest Disclosures}

The authors declare that they have no conflicts of interest.

\section{Ethical Approval}

Not applicable. 


\section{References}

1. Opitz CF, Blindt R, Blumberg F, et al. Pulmonary hypertension: Hemodynamic evaluation. Updated Recommendations of the Cologne Consensus Conference 2011. Int J Cardiol. 2011;154 Suppl 1:S13-19. doi:10.1016/s0167-5273(11)70489-2.

2. Farber HW, Loscalzo J. Pulmonary arterial hypertension. N Engl JMed. 2004;351(16):1655-1665. doi:10.1056/NEJMra035488.

3. Abe K, Toba M, Alzoubi A, et al. Formation of plexiform lesions in experimental severe pulmonary arterial hypertension. Circulation. 2010;121(25):2747-2754. doi:10.1161/circulationaha.109.927681.

4. Rubin LJ. Primary pulmonary hypertension. N Engl J Med. 1997;336(2):111-117. doi:10.1056/nejm199701093360207.

5. Lee JK, Kodama I, Honjo H, Anno T, Kamiya K, Toyama J. Stage-dependent changes in membrane currents in rats with monocrotaline-induced right ventricular hypertrophy. Am J Physiol. 1997;272(6 Pt 2):H2833-2842. doi:10.1152/ ajpheart.1997.272.6.H2833.

6. Umar S, Lee JH, de Lange E, et al. Spontaneous ventricular fibrillation in right ventricular failure secondary to chronic pulmonary hypertension. Circ Arrhythm Electrophysiol. 2012;5(1):181-190. doi:10.1161/circep.111.967265.

7. Bandorski D, Bogossian H, Ecke A, et al. Evaluation of the prognostic value of electrocardiography parameters and heart rhythm in patients with pulmonary hypertension. Cardiol J. 2016;23(4):465-472. doi:10.5603/CJ.a2016.0044.

8. Malaczynska-Rajpold K, Komosa A, Blaszyk K, et al. The Management of Supraventricular Tachyarrhythmias in Patients with Pulmonary Arterial Hypertension. Heart Lung Circ. 2016;25(5):442-450. doi:10.1016/j.hlc.2015.10.008.

9. Cannillo M, Grosso Marra W, Gili S, et al. Supraventricular Arrhythmias in Patients With Pulmonary Arterial Hypertension. Am J Cardiol. 2015;116(12):1883-1889. doi:10.1016/j. amjcard.2015.09.039.

10. Wen L, Sun ML, An P, et al. Frequency of supraventricular arrhythmias in patients with idiopathic pulmonary arterial hypertension. Am J Cardiol. 2014;114(9):1420-1425. doi:10.1016/j.amjcard.2014.07.079.

11. Kanmanthareddy A, Reddy YM, Boolani H, et al. Incidence, predictors, and clinical course of atrial tachyarrhythmias in patients with pulmonary hypertension. J Interv Card Electrophysiol. 2014;41(1):9-14. doi:10.1007/s10840-0149928-5.

12. Olsson KM, Nickel NP, Tongers J, Hoeper MM. Atrial flutter and fibrillation in patients with pulmonary hypertension. Int J Cardiol. 2013;167(5):2300-2305. doi:10.1016/j. ijcard.2012.06.024.

13. Rottlaender D, Motloch LJ, Schmidt D, et al. Clinical impact of atrial fibrillation in patients with pulmonary hypertension. PLoS One. 2012;7(3):e33902. doi:10.1371/journal.pone.0033902.

14. Ruiz-Cano MJ, Gonzalez-Mansilla A, Escribano $P$, et al. Clinical implications of supraventricular arrhythmias in patients with severe pulmonary arterial hypertension. Int J Cardiol. 2011;146(1):105-106. doi:10.1016/j.ijcard.2010.09.065.

15. Tongers J, Schwerdtfeger B, Klein G, et al. Incidence and clinical relevance of supraventricular tachyarrhythmias in pulmonary hypertension. Am Heart J. 2007;153(1):127-132. doi:10.1016/j.ahj.2006.09.008.

16. Bandorski D, Bogossian H, Stempfl J, et al. Prognostic Relevance of Nonsustained Ventricular Tachycardia in Patients with Pulmonary Hypertension. Biomed Res Int. 2016;2016:1327265. doi:10.1155/2016/1327265

17. Bandorski D, SchmittJ, Kurzlechner C, et al. Electrophysiological studies in patients with pulmonary hypertension: a retrospective investigation. Biomed Res Int. 2014;2014:617565. doi:10.1155/2014/617565.

18. Folino AF, Bobbo F, Schiraldi C, et al. Ventricular arrhythmias and autonomic profile in patients with primary pulmonary hypertension. Lung. 2003;181(6):321-328. doi:10.1007/ s00408-003-1034-x.

19. Sun PY, Jiang X, Gomberg-Maitland $M$, et al. Prolonged QRS duration: a new predictor of adverse outcome in idiopathic pulmonary arterial hypertension. Chest. 2012;141(2):374-380. doi:10.1378/chest.10-3331.

20. Hong-liang Z, Qin L, Zhi-hong L, et al. Heart rate-corrected QT interval and QT dispersion in patients with pulmonary hypertension. Wien Klin Wochenschr. 2009;121(9-10):330333. doi:10.1007/s00508-009-1184-9.

21. Rich JD, Thenappan T, Freed B, et al. QTC prolongation is associated with impaired right ventricular function and predicts mortality in pulmonary hypertension. Int J Cardiol. 2013;167(3):669-676. doi:10.1016/j.ijcard.2012.03.071.

22. Camm AJ, Kirchhof $P$, Lip GY, et al. Guidelines for the management of atrial fibrillation: the Task Force for the Management of Atrial Fibrillation of the European Society of Cardiology (ESC). Eur Heart J. 2010;31(19):2369-2429. doi:10.1093/eurheartj/ehq278.

23. Casella M, Carbucicchio C, Russo E, et al. Electrical storm in systemic sclerosis: Inside the electroanatomic substrate. World J Cardiol. 2014;6(10):1127-1130. doi:10.4330/wjc. v6.i10.1127.

24. Medi C, Kalman JM, Ling LH, et al. Atrial electrical and structural remodeling associated with longstanding pulmonary hypertension and right ventricular hypertrophy in humans. J Cardiovasc Electrophysiol. 2012;23(6):614-620. doi:10.1111/ j.1540-8167.2011.02255.x.

25. Showkathali R, Tayebjee MH, Grapsa J, et al. Right atrial flutter isthmus ablation is feasible and results in acute clinical improvement in patients with persistent atrial flutter and severe pulmonary arterial hypertension. Int J Cardiol. 2011;149(2):279-280. doi:10.1016/j.ijcard.2011.02.059.

26. Bradfield J, Shapiro S, Finch W, et al. Catheter ablation of typical atrial flutter in severe pulmonary hypertension. J Cardiovasc Electrophysiol. 2012;23(11):1185-1190. doi:10.1111/j.15408167.2012.02387.x.

27. Luesebrink U, Fischer D, Gezgin F, et al. Ablation of typical right atrial flutter in patients with pulmonary hypertension. Heart Lung Circ. 2012;21(11):695-699. doi:10.1016/j. hlc.2012.06.005. 